\title{
Modelling and simulation of heat penetration in palm fruitlets during thermal treatment process
}

\author{
${ }^{1,3}$ Shehu, U.E., ${ }^{1}$ Baharuddin, A.S., ${ }^{2}$ Nawi, N.M. and ${ }^{2 *}$ Mokhtar, M.N. \\ ${ }^{I}$ Department of Process and Food Engineering, Faculty of Engineering, Universiti Putra Malaysia, Serdang \\ 43400, Selangor Malaysia \\ ${ }^{2}$ Department of Agricultural and Biological Engineering, Faculty of Engineering, Universiti Putra \\ Malaysia, Serdang 43400, Selangor Malaysia \\ ${ }^{3}$ Department of Agricultural and Bio-environmental Engineering, College of Engineering, Kaduna \\ Polytechnic, Kaduna, P.M.B. 2021, Kaduna Nigeria.
}

Article history:

Received: 7 June 2018

Received in revised form: 8

September 2018

Accepted: 27 October 2018

Available Online: 6

November 2018

Keywords:

Palm fruit,

Endogenous lipase,

Free fatty acid,

Heat treatment,

Sterilization,

Simulation.

\section{DOI:}

https://doi.org/10.26656/fr.2017.3(2).120

\begin{abstract}
Crude palm oil (CPO) is derived from the fleshy mesocarp of the oil palm fruits, Elaeis guineensis. The mesocarp of the fruit contained an endogenous enzyme (lipase), which is activated upon detachment or bruising of the fruit. The lipolytic activity of the enzyme leads to the accumulation of free fatty acid (FFA) which is a major quality index of CPO. Heat treatment is used to substantially inactivate the lipase in the mesocarp fibre of palm fruitlets. However, the current practice of using steam has been faced with the challenges of improper steam distribution within the vessel which in conjunction with the complex matrix of the bunch and whole loading of the fruit bunch into the sterilizer brings about the differential cooking of the fruit, thereby causing partial inactivation of the enzyme. A COMSOL Multiphysics 5.3 was used to simulate heat treatment of the fruit using hot water. The simulation results reveal that the surface temperature of the kernel will attain at $70^{\circ} \mathrm{C}$ within 50 mins when submerged in hot water at $70^{\circ} \mathrm{C}$. A series of experiments were also conducted to verify whether a temperature of $70^{\circ} \mathrm{C}$ will completely inactivate the enzyme. The result shows that the residual activity of the lipase was inactivated completely after 50 mins of heat treatment at $70^{\circ} \mathrm{C}$. Since simulation result shows that the surface temperature of the kernel will be $70^{\circ} \mathrm{C}$ when the fruit is heat treated at that temperature, therefore, it implies that heat treatment of the fruit with hot water at $70^{\circ} \mathrm{C}$ will be an effective heat treatment to inactivate the endogenous lipase of palm fruits.
\end{abstract}

\section{Introduction}

Heat treatment is one of the most common methods of industrial raw material and food processing. Biological materials such as wood, grains and fruits have microscopic capillaries and pores which cause a mixture of transfer mechanisms to occur simultaneously during heat treatment (Kulasiri and Samarasinghe, 1996). Oil palm fruit (Elaeis guineensis) from which crude palm oil (CPO) is extracted being a biological material is made up of a multiplex matrix consisting of cellulose fibre as its building structure with lipid cells, water, enzyme (e.g. lipase) and some microelements filling-up the pore spaces. These compositions made the analysis of heat transfer mechanisms through it a challenging task. However, there is an understanding among researchers that conduction is the most dominant heat transfer mechanism within the fruits during heat treatment processes. Though the rate of heat conduction in the fruit is influenced by the internal parameters such as physical and thermal properties and the external parameters such as heating medium. The variations in this parameters are responsible for the non-uniformity of heat transfer in the fruit which is one of the main obstacles to the industrialisation of heat treatment of palm fruits.

The activity of lipase in the mesocarp of palm fruit is activated upon abscission or bruise that may occur during handling and processing leading to accumulation of free fatty acid (FFA) in the fruit. FFA is a major quality index of CPO internationally and to some extent determines the price of the commodity oil. To curb this menace, fresh palm fruits are sterilized with steam to inactivate or stop the lipolytic activity of the enzyme and ease the fruits stripping process (Tan et al., 2009). However, during this process, the whole fresh fruit 
bunches (FFB) are loaded into cages and are subjected to high-pressure steam 2.76 bars for about 70 to 90 mins (Sivasothy et al., 2005). But due to variation in sizes of FFB, in addition to the close-knitted matrix or arrangement of spikelet and the depth of the inner layers hinder penetration of heat. This may result in an ineffective sterilization process which is responsible for the high percentage of unstripped bunches (USB) and contributes to partial inactivation of lipase leading to enzymatic hydrolysis of $\mathrm{CPO}$ in subsequent unit operations. Sivasothy et al. (2005) reported that an attempt has been made to solve the problem of ineffective penetration of heat in FFB through the introduction of the continuous sterilization. This method involves chopping or splitting the FFB into spikelet, heating the chopped FFB and transferring it into a sterilizer vessel by a conveyor.

Fatin and Rosnah (2014) reported that the processes of the continuous sterilizer cause a lot of oil loss in condensate and oil palm stalks. Junaidah et al. (2015) also reported issues with current sterilization processes to be high oxidation risks and over-sterilization that may lead to poor bleachability of the resultant oil. The process performance has also been reported to be limited due to the inherent temperature gradient and difficult process control (Zaror et al.,1993). In addition, Sivasothy et al. (1992) reported that CPO quality is influenced by heating parameters of the process. These challenges, therefore, will definitely contribute to a great extent of deterioration of CPO quality. Steaming duration of the process has also been reported by Junaidah et al. (2015) to have contributed to the accumulation of FFA in CPO. This observation is consistent with the report by Cong and Gapor (1985), and Lau et al. (2006) who reported that the percentage of FFA reflects the degree of hydrolysis of oil, which is possibly caused by the presence of moisture under prolonged heating (extended heating time). Apart from the extended heating time, Junaidah et al. (2015) also reported that at a constant time but increased temperature, there is an increment in FFA. Hence, the temperature of the sterilization steam and the duration of heating are paramount to obtaining high-quality $\mathrm{CPO}$ in terms of FFA content. The heating medium in both the conventional/traditional sterilization process is steam, which is faced with the challenges stated above. Hence, the need to explore the use of liquid water as a heating medium for the inactivation of the endogenous lipase in palm fruits.

According to Wang et al. (2001), some heat application methods have resulted in non-uniform heating of fruit and caused a reduction in general quality attributes (firmness, fruit colour, pitting, bruising, etc).
Heat transfer to the inner portions of food materials during conventional heating is limited by their low thermal conductivity, thus prolonged heating is necessary in many cases (Lu et al., 2007). Heating times to bring the fruit centre to the desired temperatures range from 23 mins for cherry to 6 hrs for apple (Wang et al., 2001). However, in bulk processing, the heating field to which each individual commodity is exposed can hardly be the same, leading to treatment differences among products. Low specific heat capacity and poor heat transferability of conventional heating media can cause problems, making it difficult to obtain uniform heating within each individual fruit.

The objectives of this study is therefore, to develop from theory a heat transfer simulation model for palm fruit immersed in heated water using COMSOL multiphysics 5.3 and to use the model to determine the heat penetration profile within the oil palm fruit with a view to gain insight into appropriated temperature and duration of heat treatment adequate for total inactivation of the lipase.

\section{Materials and methods}

Heat penetration in palm fruitlets is a process of heat transfer that combined both convective and conductive forms of heat transfer. Heat is transfer by convective from the medium in this case water to the surface of the fruit and by conduction through the solid mass of the fruit. To simulate this process in COMSOL the following steps were followed.

\subsection{Geometry modelling.}

Based on the subject's shape and the condition of the problem, a model in 1D, 2D, 2D-axisymmetric or 3D space coordinate system can be run in COMSOL 5.3. The geometry of most fruits, such as cherries, apples and oranges, can be characterized as a spherical shape. However, Yunus et al. (2015) suggested that for simulation purposes, the fruit can be modelled as an ellipsoidal shape. Hence, the fruit was modelled as that shape, and due to the rotational symmetry of an ellipsoid, a 2D-axisymmetric space coordinate was chosen. The dimensional parameters of the palm fruit used for the geometry were taken from Owolarafe et al. (2007), as shown in Table 1. It was assumed that the domains are concentric (Figure 1a). The finalized geometry as shown in Figure $1 \mathrm{~b}$ has 2 domains (mesocarp and kernel), 7 boundaries, and 6 vertices.

Table 1. Physical properties of palm fruit (Tenara)

\begin{tabular}{cc}
\hline Property & Value $(\mathrm{mm})$ \\
\hline Length & 35.96 \\
Width & 20.15 \\
Thickness & 17.11 \\
\hline
\end{tabular}

Adapted from Owolarafe et al. (2007)

(C) 2018 The Authors. Published by Rynnye Lyan Resources 


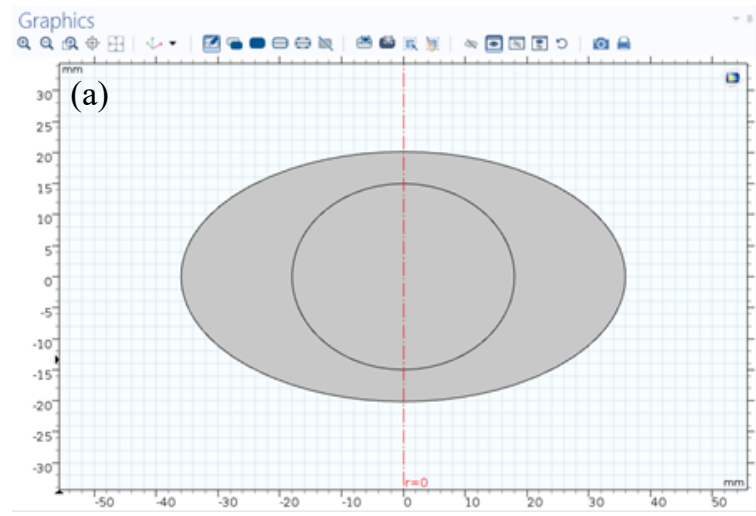

Figure 1. Model geometry of palm fruit in 2D Axisymmetric. showing the two domains

The geometry was then meshed using the fine mesh option of the software. The Completed mesh consists of 758 domain elements and 86 boundary elements (Figure 2).

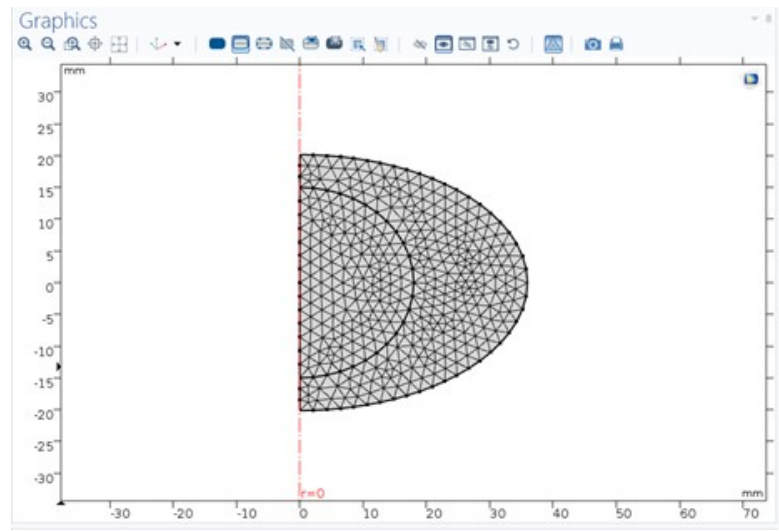

Figure 2. The meshed geometry

\subsection{Heat transfer model}

The source of thermal energy in conventional heating is hot air/or water and therefore, the temperature distribution in fruits during heat treatment is a function of radial position and treatment time. Thermal energy is transferred from the heating medium to the fruit surface $\left(r=r_{\mathrm{o}}\right)$ by convection as described by the following boundary heat flux equation (Wang et al., 2001):

$$
\begin{array}{c|c}
-k \frac{\partial T}{\partial r} \\
\text { Heat flow into fruit }
\end{array} \mid r=r_{\mathrm{o}}=\begin{gathered}
h\left[T\left(r_{\mathrm{o}}, t\right)-T_{\mathrm{e}}\right] \\
\begin{array}{c}
\text { Heat flow from heating medium } \\
\text { (Convection to heat fruit surface) }
\end{array}
\end{gathered}
$$

Where $k$ is the thermal conductivity of the fruit $\left(\mathrm{Wm}^{-1} \mathrm{~K}^{-1}\right)$; and $h$ is the surface heat transfer coefficient $\left(\mathrm{W} \mathrm{m}{ }^{-2} \mathrm{~K}^{-1}\right)$.

The heat transfer module comes with a library of heat transfer coefficient functions, $r$ is the radial coordinate originate from the fruit centre, $r_{\mathrm{o}}$ is the fruit radius $(\mathrm{m}), t$ is the treatment time $(\mathrm{min}), T$ is fruit temperature $(\mathrm{K})$, and $T_{\mathrm{e}}$ is the heating medium temperature $(\mathrm{K})$.

The moment heat energy is transferred to the surface

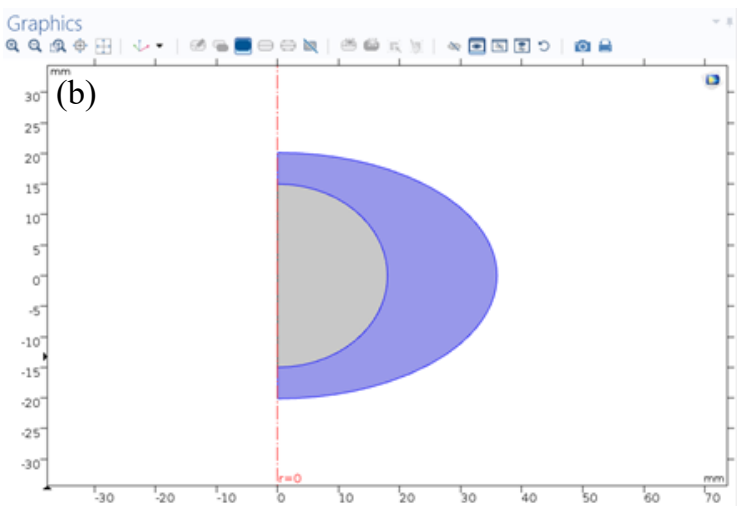

a) Ellipsoidal geometry; b) symmetry of the model geometry of the fruit; it moves into the interior by conduction. Fruit temperature as a function of time at any locations within spherical fruit is governed by a general energy balance equation given by Holdsworth (1997) as:

$$
\begin{aligned}
& \rho C_{\mathrm{p}} \frac{\partial T}{\partial t}=k\left(\frac{\partial^{2} T}{\partial^{2} r}+\frac{2}{r} \frac{\partial T}{\partial r}\right) \underset{\text { Heat generation }}{+} \\
& \text { Heating rate Heat conduction within fruit }
\end{aligned}
$$

Where $C_{\mathrm{p}}$ is the specific heat of the fruit $\left(\mathrm{J} \mathrm{kg}^{-1} \mathrm{~K}^{-1}\right) ; Q$ is the heat generation within the fruit $\left(\mathrm{Wm}^{-3}\right)$; and $\rho$ is the fruit density $\left(\mathrm{kg} \mathrm{m}^{-3}\right)$.

Relative to externally applied energy, the heat of respiration is small over the period of heat treatment. Thus, $Q=0$. Dividing by $\rho C_{\mathrm{p}}$ and substituting $\alpha$ for $k /$ $\rho C_{\mathrm{p}}$, Equation 2 becomes:

$$
\frac{\partial T}{\partial t}=\alpha\left(\frac{\partial^{2} T}{\partial^{2} r}+\frac{2}{\mathrm{r}} \frac{\partial T}{\partial r}\right)
$$

Where $\alpha$ is the thermal diffusivity $\left(\mathrm{m}^{2} \mathrm{~s}^{-1}\right)$.

\subsection{Physics settings}

The physics menu contains two settings, which are subdomain setting and boundary setting. Subdomain setting is for each domain's material properties, initial conditions and etc. Boundary setting is for boundary conditions in two aspects. Firstly, it can be used to set boundary conditions on the interface of different materials. Secondly, it can also be used to set boundary conditions on the interface between the material and the environment. The physics used for the simulation is the built-in time-dependent heat transfer in solid.

In the setting window of the software under timedependent, there is an option to choose the default heat transfer model, either fluid or solid can be chosen. In this case, it was taken to be solid. In the area where the domain can be set, all of the domains must be chosen (kernel and mesocarp). The fruit (ellipsoidal shape geometry) was set to an initial temperature of $26^{\circ} \mathrm{C}$ and the environment (water) was set to temperatures of $35^{\circ} \mathrm{C}$, $40^{\circ} \mathrm{C}, 45^{\circ} \mathrm{C}, 50^{\circ} \mathrm{C}, 60^{\circ} \mathrm{C}$ and $70^{\circ} \mathrm{C}$. The temperature 
dependent properties of the heating medium (water) are in-built in the software and shown in Table 2. While the required properties of the fruit are shown in Table 3 were entered into the appropriate fields in the physics window. The governing equations were solved by default as a time-dependent study with the recorded time step of 1 min between times 0 min and 90 mins.

Table 2. Physical properties of liquid water

\begin{tabular}{lcc}
\hline \multicolumn{1}{c}{ Property } & At $300 \mathrm{~K}$ & At $325 \mathrm{~K}$ \\
\hline Density $\left(\mathrm{kg} / \mathrm{m}^{3}\right)$ & 997 & 987 \\
Viscosity $\left(\mathrm{Ns} / \mathrm{m}^{2}\right)$ & $8.5 \times 10^{-4}$ & $5.3 \times 10^{-4}$ \\
Thermal conductivity $(\mathrm{W} / \mathrm{mK})$ & 0.62 & 0.66 \\
Heat capacity $(\mathrm{J} / \mathrm{kgK})$ & 4180 & 4182 \\
Diffusivity $\left(\mathrm{m}^{2} / \mathrm{s}\right)$ & $2.0 \times 10^{-9}$ & $2.0 \times 10^{-9}$ \\
\hline
\end{tabular}

Table 3. Physical properties of a palm fruit

\begin{tabular}{lccc}
\hline \multicolumn{1}{c}{ Property } & $\begin{array}{c}\text { Part of } \\
\text { Palm Fruit }\end{array}$ & Value & Unit \\
\hline \multirow{2}{*}{ Density $(\rho)$} & Mesocarp & 993 & $\mathrm{~kg} / \mathrm{m}^{3}$ \\
& Kernel & 1203 & $\mathrm{~kg} / \mathrm{m}^{3}$ \\
Specific Heat $(\mathrm{Cp})$ & Mesocarp & 2.816 & $\mathrm{~kJ} / \mathrm{kgK}$ \\
& Kernel & 2.291 & $\mathrm{~kJ} / \mathrm{kgK}$ \\
Thermal Conductivity & Mesocarp & 0.347 & $\mathrm{~W} / \mathrm{mK}$ \\
$(\mathrm{k})$ & Kernel & 0.529 & $\mathrm{~W} / \mathrm{mK}$ \\
Thermal Diffusivity & Mesocarp & 1.24 & $\mathrm{~m}^{2} / \mathrm{s} \mathrm{x} \mathrm{10^{-7 }}$ \\
$(\alpha)$ & Kernel & 1.92 & $\mathrm{~m}^{2} / \mathrm{s} \mathrm{x} \mathrm{10-}^{7}$ \\
\hline
\end{tabular}

Adapted from Hadi et al. (2015)

\subsection{Experimental}

The experiment was conducted with fresh palm fruits (tenara) to find out an appropriate water temperature and duration of treatment that will completely inactivate the endogenous lipase. In this study, the amount of FFA accumulated per unit time after heat-treated fruits are mashed is considered as the enzyme activity.

\subsubsection{Materials}

Fresh and ripe fruit bunches of the oil palm (Elaeis guineensis Jacq. var. tenera) were obtained from the University Putra Malaysia farm. The fruits bunches are from palm fruit trees that are 10 years old. The fruits were removed from the bunch immediately they arrived at the lab. They are cleaned, surface-sterilized in $95 \%$ ethanol for 10 mins, and washed in sterile distilled water (Tang et al., 2017). The bruised and rotten fruits were handpicked and the remaining sorted fruits were gently mixed with hand to avoid bruise and to give a homogeneous lot. The lot was randomly divided into 6 groups (A, B, C, D, E, F, and G), each with an equal weight of $1200 \mathrm{~g}$.

\subsubsection{Heat treatments of fresh palm fruit}

The 6 groups were allotted to the heat treatments i.e. group $\mathrm{A}, \mathrm{B}, \mathrm{C}, \mathrm{D}, \mathrm{E}$, and $\mathrm{F}$ were allotted heat treatment of $35^{\circ} \mathrm{C}, 40^{\circ} \mathrm{C}, 45^{\circ} \mathrm{C}, 50^{\circ} \mathrm{C}, 60^{\circ} \mathrm{C}$, and $70^{\circ} \mathrm{C}$ respectively while group $\mathrm{G}$ served as control without any treatment but was directly cooked in a boiling water for 30 mins Thermal inactivation experiments were conducted in a water bath (model DH WSB01018 Daihan WiseBath, South Korea) at temperatures of $35^{\circ} \mathrm{C}, 40^{\circ} \mathrm{C}, 45^{\circ} \mathrm{C}, 50^{\circ}$ $\mathrm{C}, 60^{\circ} \mathrm{C}$, and $70^{\circ} \mathrm{C}$. During the heat treatment, 2 Samples (1 and 2) were withdrawn from the water bath at an interval of 5 mins through 60 mins. A similar procedure was carried on group $G$ except there was no initial inactivation heat treatment.

\subsubsection{Lipase activity measurement}

Immediately after the samples were withdrawn from the water bath, the flesh (mesocarp) was peeled off from each fruit of sample 1 . The peeled mesocarp was mashed in a mortal and incubated in an incubator at $37^{\circ} \mathrm{C}$ for 10 mins thereafter, the mash was wrapped in a polyethylene bag and immersed in a boiling water for 30 mins to stop the activity of the enzyme initiated as result of mashing and incubation. While sample 2 was immersed in a boiling water for 30 mins to completely inactivate any residual enzyme thereafter the mesocarp was peeled from the kernel and mashed. All experiments were carried out in triplicate.

\subsubsection{Detection of the product}

This step refers to that process by which the product of in vivo enzyme (lipase) activity is located, identified, and the amount formed during a specific incubation interval is quantified. In this case, the product is the free fatty acid (FFA). To detect and quantify FFA liberated in the mashed mesocarp, the oil was extracted from the two samples (1 and 2). This was done by using a laboratory scale screw press. The FFA liberated in sample 1 was termed FFA1 and the one liberated in sample 2 was termed FFA2 while the one liberated in group $\mathrm{G}$ was termed $\mathrm{FFA}_{\mathrm{i}}$

\subsubsection{Determination of FFA content.}

The FFA content of the crude palm oil (CPO) extracted was determined using AOCS Method Ab 5-49 (AOCS, 2004). The percentages of FFA was calculated as palmitic acid (molecular weight $=256.6$ ) per $7 \mathrm{~g}$ of $\mathrm{CPO}$, considering palmitic acid to be the predominant fatty acid present in palm oil. Hence,

$$
\mathrm{FFA}=\frac{\mathrm{N} . \mathrm{V} .256 .6}{\mathrm{~W}}
$$

Where $\mathrm{N}$ is the normality of $\mathrm{NaOH}(0.5 \mathrm{~mol} / \mathrm{L})$; $\mathrm{V}$ is the volume of $\mathrm{NaOH}$ used; and $\mathrm{W}$ is the weight in $(\mathrm{g})$ of the sample.

The lipase activity (LA) was computed using Equation 5 and the lipase activity relative to the initial activity in an untreated fruit (RLA) using Equation 6. 


$$
\mathrm{LA}=\frac{\mathrm{FFA} 1-\mathrm{FFA} 2}{\mathrm{t}}
$$

Where $\mathrm{t}$ is the mashing time + incubation time in mins.

$$
\mathrm{RLA}=\frac{\mathrm{LA}}{\mathrm{LA}_{0}} \times 100
$$

Where $\mathrm{LA}_{0}$ is the lipase activity in the untreated fruit.

\section{Results and discussion}

\subsection{Temperature distribution}

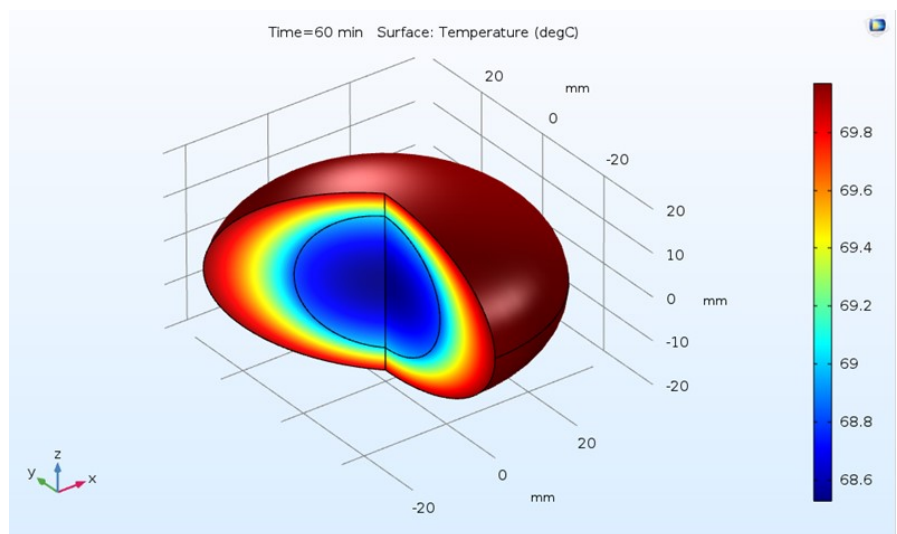

Figure 3. Temperature distribution in the fruit immersed in water at $70^{\circ} \mathrm{C}$ for 60 mins.

Figures 3 shows a uniform temperature penetration into the fruit when immersed in water at different temperatures. From Figure 3, it can be seen that after 60 mins of heat treating the fruit in water at $70^{\circ} \mathrm{C}$, the kernel surface temperature attained $69^{\circ} \mathrm{C}$, which approximately equal to the $70^{\circ} \mathrm{C}$ temperature identified in Figure 4 as a temperature that reduced the lipase activity substantially. It is also evident in Figure 3 that the temperature of domain 1 (mesocarp) is higher than the kernel surface temperature, hence, the native lipase in the mesocarp was inactive or denatured. The plots also indicate a deeper heat penetration in $\mathrm{y}$-axis compared with $\mathrm{x}$ and $\mathrm{z}$-axis even though the kernel surface temperature is the same at all the axis.

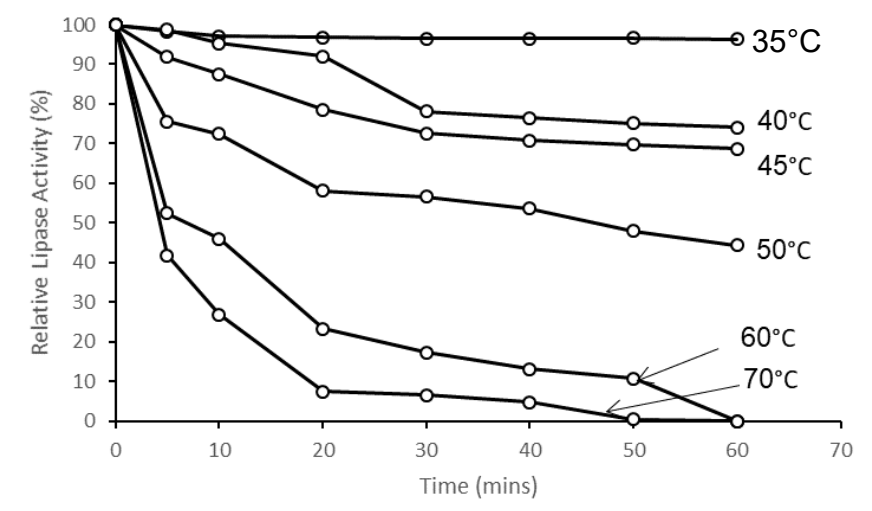

Figure 4. Relative residual lipase activity after heat treatment of the fruit in hot water at different temperatures

The objective of the palm fruit sterilisation process is to inactivate the native lipase in the mesocarp fibre of the fruit which caused FFA accumulation in CPO. As it is shown in Figure 5, heat treatment of palm fruit in hot water at $70^{\circ} \mathrm{C}$ for 60 mins is enough to stop the activity of the enzyme and will help to remove the heavy dirt, pesticides and fungal spores on the freshly harvested produce and also improve general product appearance and maintain product quality.

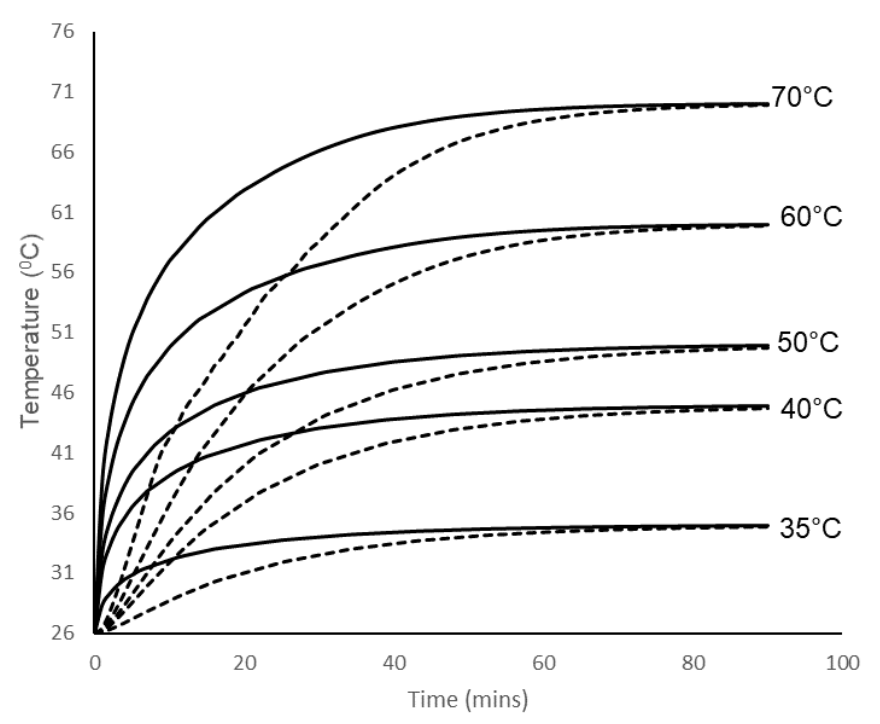

Figure 5. Simulated temperature profile of a palm at different hot water temperatures (- mesocarp temperature, kernel surface temperature)

\section{Conclusion}

A 2D-asymmetric time-dependent model using COMSOL Multiphysics ${ }^{\circledR}$ software was developed to simulate the temperature changes in the mesocarp of palm fruit immersed in heated water. The geometrical shape (ellipsoidal) used for the simulation fitted very well with the actual shape of the fruit. Although this modelling illustrates the basic heat transfer for a single product based on the assumption of ellipsoidal shape, the software was able to accurately simulate changes in temperature in the fruit with time. The relatively low temperature of $70^{\circ} \mathrm{C}$ compared with the $120^{\circ} \mathrm{C}$ steam temperature used in conventional palm fruit sterilizers and the shorter exposure time in hot water immersions treatments make hot water immersion a viable alternative. A comparative study between the convention steam sterilization and hot water immersion in terms of heat penetration and residual lipase activity as well as energy consumption, oil extraction rate (OER) and quality of CPO should be conducted.

\section{Acknowledgements}

The authors gratefully acknowledge the support of this work by the Universiti Putra Malaysia through Putra Grant (GP-IPS/2018/96350) and financial support to Shehu U.E. by the Kaduna Polytechnic, Kaduna, Nigeria. 


\section{References}

AOCS. (2004). Official methods and recommended practices of the American Oil Chemists' Society. USA: American Oil Chemists' Society.

Cong, C.L. and Gapor, M.T.A. (1985). Effects of moisture and trace metals on oil quality. In Proceedings of workshops on quality in the palm oil industry, p. 46-66. Bangi, Malaysia: Palm Oil Research Institute Malaysia.

Fatin, S.A. and Rosnah, S. (2014). Effect Of Chopping Oil Palm Fruit Spikelets on the Free Fatty Acid Content Release Rate and Its Mechanical Properties. IJRET: International Journal of Research in Engineering and Technology, 3(1), 511-516. https:// doi.org/10.15623/ijret.2014.0301086

Hadi, A.A., Mohammad, A.W. and Takriff, M.S. (2015). Spreadsheet Modelling for Temperature Profile inside Palm Oil Fresh Fruit Bunch. Journal of Industrial Engineering Research, 1(6), 25-32.

Holdsworth, S.D. (1997). Thermal Processing of Packaged Foods. London: Blackie Academic and Professional.

Junaidah, M.J., Norizzah, A.R., Zaliha, O. and Mohamad, S. (2015). Optimisation of sterilisation process for oil palm fresh fruit bunch at different ripeness. International Food Research Journal, 22 (1), 275-282.

Kulasiri, D. and Samarasinghe, S. (1996). Modelling heat and mass transfer in drying of biological materials: a simplified approach to materials with small dimensions. Ecological Modelling, 86(2-3), 163-167. https://doi.org/10.1016/0304-3800(95) 00046-1

Lau, H.L.N., Choo, Y.M., Ma, A.N. and Chuah, C.H. (2006). Characterization and supercritical carbon dioxide extraction of palm oil (Elaeis Guineensis). Journal of Food Lipids, 13(2), 210-221. https:// doi.org/10.1111/j.1745-4522.2006.00046.x

Lu, J., Vigneault', C., Charles, M.T. and Raghavan, G.S.V. (2007). Heat treatment application to increase fruit and vegetable quality. Stewart Postharvest Review, 3(3). https://doi.org/10.2212/ spr.2007.3.4

Owolarafe, O.K., Olabige, M.T. and Faborode, M.O. (2007). Physical and mechanical properties of two varieties of fresh oil palm fruit. Journal of Food Engineering, 78(4), 1228-1232. https:// doi.org/10.1016/j.jfoodeng.2005.12.049

Sivasothy, K., Halim, R.M. and Basiron, Y. (2005). A New System for Continuous Sterilization of Oil Palm Fresh Fruit Bunches. Journal of Oil Palm Research, 17, 145-151.
Sivasothy, K., Ma, A.N. and Maycock, J.H. and Koichiro, Y. (1992). Combined sterilizationstripping process: A promising approach for oil quality improvement. In Proceedings of PORIM Palm Oil Quality Conference, p. 59-74. Bangi: Palm Oil Research Institute, Malaysia.

Tan, C.-H., Ghazali, H.M., Kuntom, A., Tan, C.-P. and Ariffin, A.A. (2009). Extraction and physicochemical properties of low free fatty acid crude palm oil. Food Chemistry, 113(2), 645-650. https://doi.org/10.1016/j.foodchem.2008.07.052

Tang, M., Xia, Q., Holland, B.J., Wang, H., Zhang, Y., Li, R. and Cao, H. (2017). Effects of Different Pretreatments to Fresh Fruit on Chemical and Thermal Characteristics of Crude Palm Oil. Journal of Food Science, 82(12), 2857-2863. https:// doi.org/10.1111/1750-3841.13972

Wang, S., Tang, J. and Cavalieri, R.P. (2001). Modeling fruit internal heating rates for hot air and hot water treatments. Postharvest Biology and Technology, 22 (3), 257-270. https://doi.org/10.1016/S0925-5214 (01)00085-0

Yunus, R., Zurina, Z.A., Syafiie, S. and Chang, T.S. (2015). Modeling and Simulation of Heat and Mass Transfer in Oil Palm Fruit Digestion Process. Journal of Emerging Trends in Engineering and Applied Sciences (JETEAS), 6(2), 136-143.

Zaror, C.A., Pyle, D.L. and Molnar, G. (1993). Mathematical modelling of an ohmic heating steriliser. Journal of Food Engineering, 19(1), 3353. https://doi.org/10.1016/0260-8774(93)90060-W 